\title{
Analisis tegangan keluaran generator listrik frekuensi rendah dengan metode conjugate-gradient
}

\author{
Jamrud Aminuddin \\ Program Studi Fisika, Fakultas MIPA, Universitas Jenderal Soedirman \\ Jalan Dr. Suparno No.61 Karangwangkal Purwokerto Jawa Tengah \\ email: jamrud.aminuddin@unsoed.ac.id
}

\begin{abstract}
Abstrak- Analisis numerik terhadap tegangan keluaran generator listrik berdasarkan persamaan induksi elektromagnetik telah dilakukan dengan metode conjugate-gradient. Parameter fisis yang digunakan sebagai input merupakan angka-angka hasil eksperimen dari referensi tentang generator listrik frekuensi rendah, yaitu: magnet permanen, luas penampang, dan sudut antara medan magnet dan momen magnet. Parameter yang dijadikan fungsi target dalam metode conjugate-gradient adalah jumlah lilitan pada solenoid dan tegangan keluaran yang dibangkitkan melalui energi mekanik. Hasil perhitungan menunjukkan bahwa tingkat kesalahan dengan metode ini sekitar 5\%. Secara keseluruhan, analisis numerik ini menunjukkan bahwa tegangan keluaran dapat diseimbangkan melalui pengaturan jumlah solenoid dan kecepatan putaran generator
\end{abstract}

Kata Kunci: conjugate-gradient, generator, induksi, solenoid, tegangan

Abstract - - The numerical analysis of the output voltage of the electric generators based on the electromagnetic induction equation has been carried out using the conjugate-gradient method. The physical parameters used as constant numbers are from the experimental results of the electric generator with lower frequency, i.e.: the permanent magnet, cross-sectional area, and the angle between the magnetic field and the magnetic moment. The other parameters considered in the conjugate gradient-method are the number of coils of the solenoid and the output voltage which is generated from the kinetic energy. The results of the calculation show that the error rate of the method is approximately 5\%. Overall, this numerical analysis shows that the output voltage can be balanced through the adjustment of the number of coils of the solenoid and the rotational speed of the generator.

Key words: conjugate-gradient, generator, induction, solenoid, voltage

\section{PENDAHULUAN}

Generator listrik merupakan alat untuk mengubah energi kinetik dalam bentuk putaran menjadi energi listrik. Generator paling sering digunakan untuk berbagai jenis sistem pembangkit, seperti: tenaga air, tenaga panas bumi, tenaga uap dan tenaga angin, serta tenaga gelombang laut $[1,2]$. Pada prinsipnya tidak semua energi kinetik yang bersumber dari alam memiliki kecepatan putaran yang tinggi untuk membangkitkan listrik. Sebagian energi tersebut hanya mampu memutar poros generator dengan kecepatan rendah. Generator yang mampu membangkitkan listrik dengan kecepatan putaran yang rendah dikenal dengan istilah generator listrik frekuensi rendah [3,4].

Ada dua buah jenis generator yang biasa digunakan, yaitu generator sinkron dan asinkron. Generator sinkron merupakan generator dengan kecepatan putar rotor sama dengan kecepatan medan putar stator seperti generator medan magnet permanen. Sedangkan generator asinkron memiliki kecepatan putar rotor yang berbeda dengan kecepatan putar medan stator seperti generator induksi. Generator induksi banyak digunakan pada pembangkit listrik skala kecil karena harganya yang lebih murah, tidak membutuhkan sikat, konstruksinya yang sederhana, serta mudah dan murah perawatannya $[5,6]$.

Generator bekerja berdasarkan prinsip induksi elektromagnetik yang terjadi pada solenoid yang digerakkan pada magnet. Sebaliknya sebuah magnet yang digerakan pada soleniod juga menimbulkan induksi elektromagnetik [2,7]. Dimensi kumparan dan besarnya medan magnet pada sebuah generator serta besarnya kecepatan pergerakan di antara keduanya dapat dibuat bervariasi berdasarkan kebutuhan daya listrik yang diinginkan [3]. Fenomena tersebut memerlukan analisis yang tepat untuk menghasilkan sebuah generator yang efektif dan efisien dalam menghasilkan arus listrik [8-10]. Metode yang selama ini dikembangkan dalam perancangan generator 
listrik adalah ekperimen. Untuk itu, dalam studi ini dikembangkan sebuah metode komputasi untuk menentukan dimensi generator sebelum eksperimen dilakukan.

Salah satu metode yang memungkinkan untuk menentukan beberapa parameter fisis terkait dengan optimasi kinerja generator adalah metode conjugate-gradient. Metode conjugategradient merupakan prosedur yang digunakan untuk menemukan minimum lokal dari fungsi yang terdiferensialkan. Metode conjugategradient juga dapat digunakan untuk mencari solusi numerik dari suatu persamaan linier tertentu yang matriksnya simetris dan definit positif. Metode ini bersifat iteratif sehingga dapat diaplikasikan pada sistem persamaan diferensial [11-13].

Berdasarkan uraian di atas maka dalam tulisan ini dilakukan analisis tegangan keluaran generator listrik frekuensi rendah untuk menghasilkan arus listrik. Metode yang digunakan merupakan pengembangan referensi [1] dan [3]. Metode untuk menganalisis dimensi kumparan dan besarnya medan magnet pada sebuah generator serta besarnya kecepatan pergerakan di antara keduanya akan dianalisis dengan metode conjugate-gradient [11-14].

\section{METODE}

Analisis gaya gerak listrik dari sebuah generator dilakukan melalui tiga tahapan utama. Ketiga tahapan tersebut adalah: perumusan persamaan gaya gerak listrik, penyusunan algortima beserta realisasinya dalam bahasa pemrograman, dan perhitungan beserta analisisnya. Perumusan persamaan yang terkait dengan generator listrik dimulai dari prinsip induksi elektromagnetik, kemudian dihubungkan dengan perubahan fluks magnetik dikenal dengan Hukum Faraday [2,7]. Persamaan gaya gerak listrik (GGL) selanjutnya dianalisis dengan menggunakan metode conjugate-gradient [11-14]. Metode ini diimplementasikan dalam bahasa pemrograman Matlab [14,15]. Analisis dilakukan terhadap banyaknya solenoid, kecepatan sudut putaran, dan tegangan keluaran generator [3].

Generator bekerja berdasarkan prinsip induksi elektromagnetik yang dapat terjadi jika sebuah kumparan digerakkan pada sebuah magnet. Dapat juga terjadi sebaliknya, sebuah magnet yang digerakkan terhadap solenoid. Solenoid merupakan kumparan kawat yang berbentuk silinder yang jarak antar lilitannya sangat rapat. Kedua benda tersebut dapat menghasilkan induksi elektromagnetik atau gaya gerak listrik induksi [2,7]. Bentuk dasar penampang generator diperlihatkan pada Gambar 1.

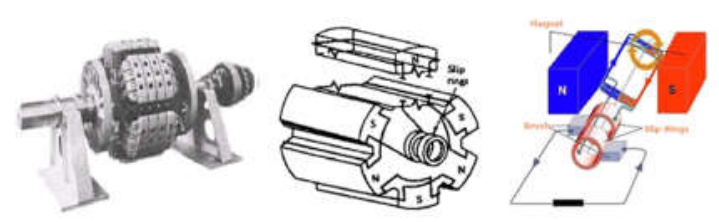

Gambar 1. Penampang generator [7]

Hubungan antara gaya gerak listrik (GGL) induksi dengan perubahan fluks magnetik dikenal dengan Hukum Faraday. Menurut percobaan Faraday, jika fluks magnetik yang melalui suatu rangkaian diubah dengan cara apapun, maka GGL induksi akan sama besar dengan laju perubahan fluks yang diinduksikan dalam rangkaian. Fluks ini dapat dihasilkan dari medan magnet dalam bentuk simpal arus. Hukum Faraday menyatakan bahwa tegangan elektrik imbas $\varepsilon$ di dalam sebuah rangkaian sama dengan kecepatan fluks yang melalui rangkaian tersebut. Jika kecepatan perubahan fluks dinyatakan di dalam Weber per detik (W.s $\left.{ }^{1}\right)$, maka tegangan gerak elektrik $\varepsilon$ akan dinyatakan dalam Volt (V). Besarnya GGL (electromagnetic force) induksi dapat dinyatakan sebagai perubahan fluks magnetik $\phi_{B}$ dalam selang waktu $(t)$ :

$$
\varepsilon=-\frac{d \phi_{B}}{d t} .
$$

Tanda negatif menunjukkan arah tegangan gerak elektrik imbas yang merupakan kontribusi dari Hukum Lenz, dengan tegangan gerak elektrik akan melawan perubahan yang diterima simpal. Jika persamaan (1) dikenakan pada sebuah solenoid dengan $N$ lilitan, maka sebuah tegangan gerak elektrik akan muncul dalam setiap lilitan. Sehingga semua tegangan gerak elektrik dapat dituliskan dalam bentuk:

$$
\varepsilon=-N \frac{d \phi_{B}}{d t}=-\frac{d\left(N \phi_{B}\right)}{d t},
$$

dengan $N \phi_{B}$ menyatakan nilai tautan fluks (fluks linkages) di dalam solenoid, $N$ adalah jumlah lilitan dan $\phi_{B}$ menyatakan fluks magnetik. Jika $\phi_{B}=N \phi_{B}$, maka persamaan (2) dapat ditulis dalam bentuk:

$$
\varepsilon=-\frac{d(N B A)}{d t}=-N B \frac{d A}{d t} .
$$


Jika $N$ dan $B$ konstan terhadap waktu, sedangkan $A$ luas penampang yang berubah terhadap sudut, dan sudut berubah tehadap waktu, maka persamaan (3) dapat dinyatakan dalam bentuk:

$$
\varepsilon=-N B \frac{d A}{d \theta} \frac{d \theta}{d t}
$$

Jika $\quad \bar{B} \cdot \bar{A}=|\bar{B}| \cdot|\bar{A}| \cos \theta$, maka persamaan (4) menjadi

$$
\varepsilon=N B A \omega \sin \theta
$$

dengan $\theta$ adalah besarnya sudut antara medan magnet dan momen magnet, dan $\omega$ adalah kecepatan sudut. Persamaan (5) menunjukkan GGL induksi yang ditimbulkan dapat diperbesar dengan memperbanyak jumlah lilitan pada solenoid, menggunakan magnet yang lebih kuat, dan mempercepat putaran generator listrik $[1,2,7]$.

Berdasarkan persamaan (5), penentuan jumlah lilitan solenoid, besarnya kecepatan radial, sudut medan magnet, dan magnet permanent dilakukan dengan metode conjugategradient. Metode tersebut adalah sebuah algoritma untuk mencari solusi numerik sistem persamaan linier yang matriksnya simetris dan definit positif. Metode ini bersifat iteratif, sehingga dapat diaplikasikan pada sistem yang sedikit kompleks jika diselesaikan dengan metode langsung. Secara matematis metode ini dimulai dengan sebuah pemahaman

$$
\min \left\{f(x): x \in R^{n}\right\}
$$

di mana $f: R^{n} \rightarrow R$ adalah fungsi yang differentiable dan terbatas. Untuk menyesaikan masalah ini, dimulai dengan memberikan nilai awal $x_{0} \in R^{n}$, sebuah metode non linear conjugate gradient, membangun barisan $\left\{x_{k}\right\}$ berdasarkan rumus:

$$
x_{k+1}=x_{k}+\alpha_{k} d_{k}
$$

dengan $\alpha_{k}>0$ diperoleh dengan metode line search dan $d_{k}$ dibangun dari:

$$
d_{k+1}=-g_{k+1}+\beta_{k} s_{k} \quad ; \quad d_{0}=-g_{0} \quad(8)
$$

dengan $\beta_{k}$ adalah parameter conjugategradient, $s_{k}=x_{x+1}-x_{k}$ dan $g_{k}=\nabla f\left(x_{k}\right)$ [11-14].

Penamaan parameter yang terkait dengan persamaan (5) dalam metode conjugate gradient, dimulai dari asumsi bahwa optimasi akan dilakukan terhadap nilai tegangan keluaran
( $\varepsilon$ ) sebagai fungsi dari jumlah lilitan $(N)$ dan kecepatan radial $(\omega)$,

$$
\varepsilon(N, \omega)=N B A \omega \sin \theta .
$$

Dari persamaan (9), maka diketahui fungsi target dalam bentuk:

$$
\partial_{N} \varepsilon(N, \omega)=B A \omega \sin \theta,
$$

dan

$$
\partial_{\omega} \varepsilon(N, \omega)=N B A \sin \theta .
$$

Parameter lainnya yang merupakan fungsi yang berpengaruh terhadap besarnya gaya-gerak listrik pada persamaan (5) dianggap sebagai konstanta hitungan numerik. Pada prinsipnya semua variabel dapat dijadikan sebagai fungsi target, tetapi setelah mempertimbangkan faktor teknis, maka parameter lainnya dianggap konstan dalam proses perhitungan dengan metode conjugate-gradient. Parameter fisis yang dianggap konstan dalam prosedur ini adalah $B$ (medan magnet), $A$ (luas penampang) dan $\theta$ (sudut antara medan magnet dan momen magnet).

Prosedur lengkap dengan metode conjugate-gradient terhadap persamaan (5) untuk menganalisis beberapa parameter fisis yang terkait dengan generator listrik adalah:

0 . Menentukan parameter yang dianggap konstan $(B, A$, dan $\theta)$, nilai awal perhitungan $\quad\left(N_{0}, \omega_{0}, \alpha_{0}^{N}, \alpha_{0}^{\omega}, \delta_{0}^{N}, \delta_{0}^{\omega}\right.$, $\left.G_{0} \equiv G_{0}^{N, \omega}, d_{0}^{N}, d_{0}^{\omega}\right), \quad$ dan melakukan estimasi awal terhadap nilai $\varepsilon_{0}$, setelah itu prosedur berikut dilakukan sampai iterasi ke- $n$ :

1. $N_{n}=N_{n-1}+\alpha_{n-1}^{\omega} d_{n-1}^{\omega}$ dan $\omega_{n}=\omega_{n-1}+\alpha_{n-1}^{N} d_{n-1}^{N}$

2. $G_{n}^{N, \omega}=\left[\partial_{N} \varepsilon(N, \omega) \quad \partial_{\omega} \varepsilon(N, \omega)\right]$

3. $\beta_{n}^{N, \omega}=\frac{G_{n}^{T} G_{n}}{G_{n-1}^{T} G_{n-1}}$ (Superscript $\mathrm{T} \cong$ transpose matriks)

4. $\delta_{n}^{N}=N_{n}-N_{n-1}$ dan $\delta_{n}^{\omega}=\omega_{n}-\omega_{n-1}$

5. $d_{n}^{N}=-G_{n}^{N}+\beta_{n} \delta_{n}^{N}$ dan $d_{n}^{\omega}=-G_{n}^{\omega}+\beta_{n} \delta_{n}^{\omega}$

6. $\quad \alpha_{n}^{N}=\alpha_{n-1}^{N} \frac{\llbracket d_{n-1}^{N} \rrbracket}{\llbracket d_{n}^{N} \rrbracket}$ dan $\alpha_{n}^{\omega}=\alpha_{n-1}^{\omega} \frac{\llbracket d_{n-1}^{\omega} \rrbracket}{\llbracket d_{n}^{\omega} \rrbracket}$

7. $d_{n}^{N}=-G_{n}^{N}+\beta_{n} \delta_{n}^{N}$ dan $d_{n}^{\omega}=-G_{n}^{\omega}+\beta_{n} \delta_{n}^{\omega}$

8. Nilai GGL pada iterasi ke- $n$ : $\varepsilon_{n}(N, \omega)=N_{n} B A \omega_{n} \sin \theta$ 
9. Error: $\eta_{n}=\left|\frac{\varepsilon_{n}-\varepsilon_{n-1}}{\varepsilon_{n-1}}\right| \times 100 \%$.

Prosedur tersebut diimplementasikan dalam pemrograman Matlab [14,15]. Hasil yang ditargetkan adalah tegangan keluaran optimum dengan jumlah lilitan dan kecepatan putaran yang bervariasi.

\section{HASIL DAN PEMBAHASAN}

Pada Gambar 2 diperlihatkan hasil estimasi dengan metode conjugate-gradient. Parameter fisis yang digunakan sebagai bilangan konstan merupakan pengujian angka-angka hasil eksperimen dari referensi. Pada referensi tersebut, digunakan magnet permanen $(B)$ sebesar 1,0833 Tesla $(\approx 0,0002$ Weber $)$, luas penampang $(A)$ sebesar $2 \mathrm{~cm}^{2}$, dan sudut antara medan magnet dan momen magnet $(\theta)$ sebesar $45^{\circ}$. Jumlah lilitan sebanyak 63 dengan tegangan keluaran sebesar $\approx 12$ Volt yang dibangkitkan dengan kecepatan putaran $500 \mathrm{rpm}$ (revolution per minute) $[2,3,9]$. Jumlah lilitan berdasarkan perhitungan komputasi berada pada angka yang hampir sama dengan ekperimen pada referensi $[2,3,9]$, yaitu pada kisaran 60 .

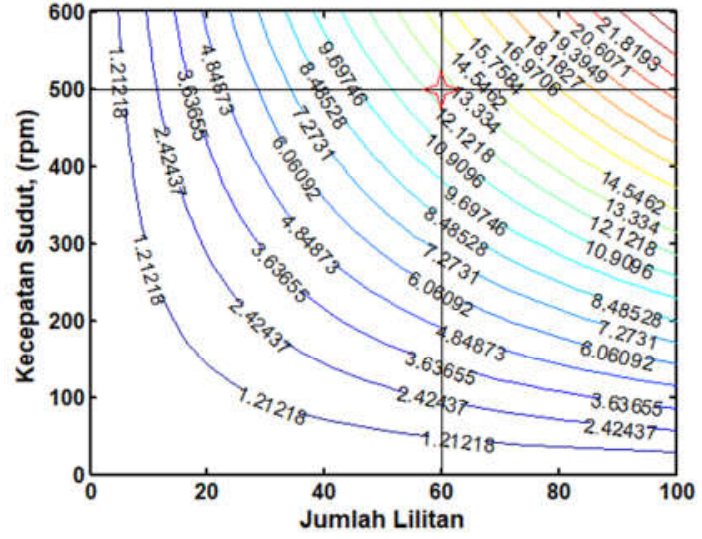

Gambar 2. Hasil perhitungan tegangan keluaran dengan metode conjugate-gradient. Garis kontur menunjukkan besarnya tegangan keluaran (Volt) berdasarkan jumlah lilitan dan kecepatan angular generator listrik.

Tegangan keluaran dengan fungsi target berupa kecepatan putaran $(\omega)$ pada angka 500 rpm menunjukkan angka antara 12-13 Volt. Hasil ini menunjukkan bahwa hasil metode conjugate-gradient dengan menggunakan angka-angka hasil eksperimen menunjukkan akurasi sekitar 95\%. Untuk itu pada perhitungan selanjutnya dilakukan variasi terhadap parameter konstan dengan asumsi bahwa tegangan keluaran berdasarkan metode conjugate-gradient dikoreksi sebesar $\pm 5 \%$. Waktu yang digunakan untuk perhitungan dalam Matlab sangat singkat karena menggunakan parameter angka yang kecil.

Tabel 1. Pengaruh magnet permanen terhadap tegangan keluaran

\begin{tabular}{cc}
\hline $\begin{array}{c}\text { Magnet permanen } \\
\text { (Weber) }\end{array}$ & $\begin{array}{c}\text { Tegangan keluaran } \\
\text { (Volt) }\end{array}$ \\
\hline 0,0001 & 6,0609 \\
0,0002 & 12,1218 \\
0,0003 & 18,1827 \\
0,0004 & 24,2437 \\
0,0005 & 30,3046 \\
0,0006 & 36,3655 \\
0,0007 & 42,4264 \\
0,0008 & 48,4873 \\
0,0009 & 54,5482 \\
\hline
\end{tabular}

Tabel 1 merupakan pengembangan hasil perhitungan dengan metode conjugate-gradient. Parameter yang dijadikan standar pada Gambar 2 adalah kecepatan putaran pada angka $500 \mathrm{rpm}$ dan jumlah lilitan pada angka 60 dengan tegangan keluaran yang terbaca pada garis kontur sebesar 10,1015 Volt. Bilangan konstan yang divariasikan pada bagian ini adalah magnet permanen, sedangkan parameter lainnya dibuat tetap. Nilai parameter konstan yang tidak divariasikan dalam perhitungan ini adalah luas penampang $(A)$ sebesar $2 \mathrm{~cm}^{2}$, dan sudut antara medan magnet dan momen magnet $(\theta)$ sebesar $45^{\circ}$. Kedua nilai tersebut diambil dari hasil eksperimen pada referensi [2,3,9]. Hasil estimasi dengan metode conjugate-gradient menunjukkan bahwa pengaruh magnet permanen yang ditingkatkan setiap 0,0001 Weber mampu meningkatkan tegangan keluaran generator lisrik sebesar 5 Volt.

Tabel 2. Pengaruh luas penampang terhadap tegangan keluaran

\begin{tabular}{cc}
\hline $\begin{array}{c}\text { Luas penampang } \\
\left(\mathrm{cm}^{2}\right)\end{array}$ & $\begin{array}{c}\text { Tegangan keluaran } \\
(\text { Volt })\end{array}$ \\
\hline 1,5 & 10,1015 \\
2,0 & 12,1218 \\
2,5 & 14,1421 \\
3,0 & 16,1624 \\
3,5 & 18,1827 \\
4,0 & 20,2031 \\
4,5 & 22,2234 \\
5,0 & 24,2437 \\
\hline
\end{tabular}

Tabel 2 merupakan pengembangan metode perhitungan pada Tabel 1 dengan parameter 
standar yang sama. Parameter yang divariasikan adalah luas penampang generator $(A)$. Nilai parameter konstan yang tidak divariasikan dalam perhitungan ini adalah magnet permanen $(B)$ sebesar 0,0002 Weber, dan sudut antara medan magnet dan momen magnet $(\theta)$ sebesar $45^{\circ}$. Parameter konstan tersebut merupakan nilai yang diperoleh dari hasil ekperimen untuk generator frekuensi rendah. Parameter yang tidak pernah divariasikan secara eksperimen adalah $\theta$ sebesar $45^{\circ} \quad[8,9]$. Nilai tersebut digunakan untuk menganalisis parameter yang ideal untuk menghasilkan tegangan keluaran pada angka $\approx 12$ Volt. Pada Tabel 1, angka yang mendekati adalah 12,1218 Volt dengan magnet permanen 0,0002 Weber sehingga nilai tersebut digunakan pada bagian ini. Hasil pada Tabel 2 menunjukkan bahwa pada magnet permanen 0,0002 Weber dengan peningkatan luas penampang $0,5 \mathrm{~cm}^{2}$ akan meningkatkan tegangan keluaran generator sebesar $\approx 2$ Volt.

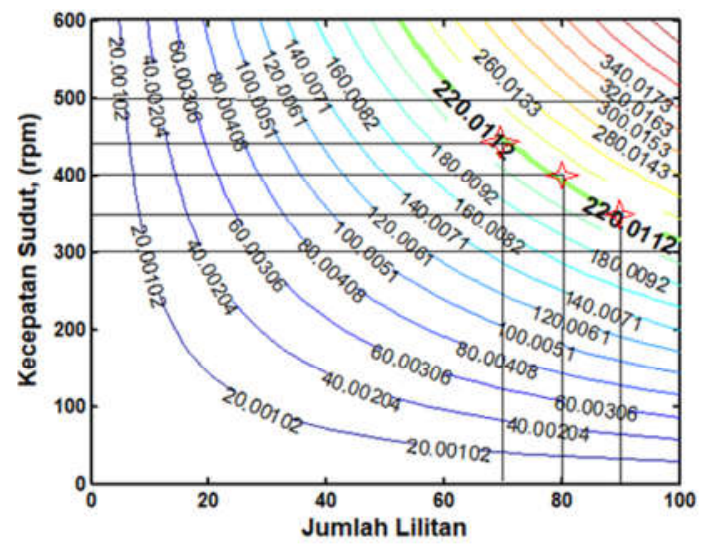

Gambar 3. Hasil perhitungan teoretis tegangan keluaran generator dengan target 220 Volt (diperlihatkan pada garis kontur). Ada tiga keadaan untuk mendapatkan nilai yang ditargetkan antara jumlah lilitan dan kecepatan.

Gambar 3 merupakan hasil estimasi rancangan generator listrik dengan daya keluaran 220 Volt. Tegangan tersebut dipilih dengan asumsi bahwa tengangan yang umum digunakan di Indonesia adalah 220 Volt [3]. Parameter fisis yang digunakan sebagai bilangan konstan merupakan pengujian secara teoretis berdasarkan kecenderungan hasil pada Tabel 1 dan 2. Fungsi target berupa jumlah lilitan dan kecepatan putaran seperti pada Gambar 3 dihasilkan melalui pengujian beberapa bilangan konstan dengan prosedur yang sama seperti pada Gambar 2. Pada pengujian ini digunakan luas penampang generator sebesar $10 \mathrm{~cm}$ dan magnet permanen 0,0009 Weber. Dengan menggunakan prinsip eksperimen maka sudut antara medan magnet dan momen magnet tidak divariasi tetapi menggunakan angka yang umum digunakan dalam pembuatan generator, yaitu sebesar $45^{\circ}$ $[8,9]$. Hasil estimasi yang telah dilakukan menunjukkan bahwa tegangan 220 Volt diperoleh pada kecepatan antara 300-450 rpm dengan jumlah lilitan antara 70-90.

Hasil ini juga memberi petunjuk bahwa untuk mendapatkan nilai tegangan yang ditargetkan, maka perlu dilakukan analisis keseimbangan antara kecepatan putaran dan jumlah lilitan $[6,8,10]$. Metode ini hanya merupakan alat bantu dalam proses pembuatan generator listrik. Dalam eksperimen dibutuhkan beberapa koreksi untuk memastikan tegangan keluaran generator listrik. Metode ini juga dapat diaplikasikan dengan mengubah fungsi target dan parameter konstan [11,13]. Berdasarkan nilai-nilai yang digunakan sebagai input yang tidak lain adalah hasil eksperimen dengan akurasi sekitar 95\%, maka metode ini sangat direkomendasikan untuk kajian optimasi lainnya.

\section{KESIMPULAN}

Analisis parameter yang berpengaruh pada kinerja generator listrik telah dilakukan secara teoretis dengan metode numerik. Perumusan dimulai dengan meninjau Hukum Faraday dan Hukum Lenz tentang gaya gerak listrik (GGL) akibat induksi elektromagnetik. Dari perumusan tersebut diperoleh persamaan tegangan keluaran generator listrik sebagai fungsi dari medan magnet, luas permukaan generator, kecepatan putaran, sudut antara medan magnet dan momen magnet, dan jumlah lilitan solenoid. Dari persamaan tersebut, ditetapkan dua buah fungsi target untuk menganalisis tegangan keluaran generator listrik dengan metode conjugategradient, yaitu kecepatan putaran dan jumlah lilitan. Fungsi lainnya dianggap sebagai parameter konstan. Parameter konstan tersebut juga divariasikan untuk mengetahui efeknya terhadap tegangan keluaran dari generator listrik.

Pengujian metode ini dilakukan dengan menggunakan data-data eksperimen yang dilakukan oleh peneliti sebelumnya yang diperoleh melalui pengukuran secara langsung. Hasil estimasi dengan metode conjugategradient menunjukkan bahwa metode ini sangat 
akurat dengan tingkat kesalahan hanya 5\%. Selanjutnya inovasi baru yang dilakukan dalam analisis numerik ini adalah estimasi keseimbangan antara jumlah lilitan dan kecepatan putaran generator dengan target keluaran disesuaikan dengan tegangan untuk instrument listrik yang umumnya digunakan di Indonesia, yaitu 220 Volt. Hasil estimasi terakhir menunjukkan bahwa untuk mencapai nilai yang ditargetkan diperlukan peningkatan jumlah lilitan untuk menekan energi untuk memutar generator listrik.

Metode conjugate-gradient yang telah diterapkan hanya merupakan alat bantu dalam proses pembuatan generator listrik. Dalam eksperimen dibutuhkan beberapa koreksi untuk memastikan tegangan keluaran generator listrik. Parameter yang digunakan untuk hasil yang terakhir belum mempunyai angka pembanding berdasarkan hasil eksperimen. Untuk itu sangat disarankan agar hasil ini dapat diimplementasikan dengan membuat prototype generator berdasarkan hasil perhitungan teoretis yang diperoleh dalam analisis ini.

\section{UCAPAN TERIMA KASIH}

Artikel ilmiah ini merupakan bagian dari kegiatan penelitian hibah bersaing dengan sumber dana Dikti, nomor kontrak: DIPA023.04.2.189899/2014. Untuk itu saya ucapkan terima kasih atas dukungan dana dalam penelitian ini. Ucapan terima kasih juga saya ucapkan kepada rekan-rekan yang tidak bisa disebutkan semuanya dalam ruang sempit ini, atas diskusinya yang sangat bermanfaat.

\section{PUSTAKA}

[1] G.A. Caxaria, D.M. Sousa, and H.M. Ramos, Small Scale Hydropower: generator analysis and optimization for water supply systems, World Renewable Energy Congress 2011 Sweden, 8-13 May Lingköping-Sweden, (2011) 1386-1393.

[2] P. Irasari, D. Hidayati, dan Nurafni, Analisis Prototipe Generator Kecepatan Rendah Untuk Pembangkit Listrik Skala Kecil, Majalah Teknologi Indonesia, 29(1) (2006) 47-51.

[3] P. Irasari, A.S. Nugraha, dan M. Kasim, Analisis Getaran pada Generator Magnet Permanen $1 \mathrm{Kw}$ Hasil Rancang Bangun
Pusat Penelitian Tenaga Listrik dan Mekatronik, Journal of Mechatronics, Electrical Power, \& Vehicular Technology 1(1) (2010) 19-26.

[4] M.E.A. Farrag, and G.A. Putrus, Analysis of the Dynamic Performance of SelfExcited Induction Generators Employed in Renewable Energy Generation, Energies 7 (2014) 278- 294.

[5] A. Gupta, and S. Wadhwani, Analysis of Self-Excited Induction Generator for Isolated System, International Journal of Computational Engineering Research (IJCER) 2(2) (2012) 353-358.

[6] M. Hadziselimovic, I. Zagradisnik, and B. Stumberger, Induction Machine: Comparison of Motor and Generator Characteristics, Acta Technica Jaurinensis 6(1) (2013) 39-47.

[7] J.D. Jackson, Classical Electrodynamics, 3rd Edition, John Wiley and Sons, USA, 1998

[8] M. Senthilkumar, Optimal Capacitor for Maximum Output Power Tracking of Self Excited Induction Generator Using Fuzzy Logic Approach, International Journal on Computer Science and Engineering (IJCSE) 2(5) (2010) 1758-1762.

[9] K. Thakur, A Reliable and Accurate Calculation of Excitation Capacitance Value for an Induction Generator Based on Interval Computation Technique, International Journal of Automation and Computing 8(4) (2011) 429 - 436.

[10] G.K. Shilpa, and P.F. Dias, Stability of Voltage Using Different Control Strategies in Isolated Self Excited Induction Generator for Variable Speed Applications, International Journal of Engineering Trends and Technology (IJEET) 4(3) (2013) 2366 - 2370.

[11] S. Sanmatías, and E.A. Vercher, Generalized Conjugate Gradient Algorithm, Journal of Optimization Theory and Applications 98 (1998) 489502. 
[12] Z. Wei, G. Li, and L. Qi, New Nonlinear Conjugate Gradient Formulas for Largescale Unconstrained Optimization Problems, Applied Mathematics and Computation 179(2) (2006) 407-430.

[13] I. Abdullahi, and R. Ahmad, Global Convergence Analysis of a New Hybrid Conjugate Gradient Method for Unconstrained Optimization Problems, Malaysian Journal of Fundamental and Applied Sciences 2(13) (2017) 40-48.
[14] G. Liendfield, and J. Penny, Numerical Methods using MATLAB. Ellis Horword Limited. New York, 1995.

[15] J. Aminuddin, Dasar-Dasar Fisika Komputasi Menggunakan MATLAB, Edisi Pertama. Gava Media. Yogyakarta, 2008. 